\section{Growing Science}

\author{
Marvin L. Birnbaum, MD, PhD
}

...I have seen that in any great undertaking, it is not enough for a man to depend simply upon himself.

Lone Man [Isna la-wica], late 19th Century, Teton Sioux

The 15th World Congress on Disaster and Emergency Medicine (Amsterdam, May 2007) is the most ambitious Congress ever convened by the World Association for Disaster and Emergency Medicine (WADEM). The record number of abstracts submitted $(>550)$ is an indication that the field of Disaster and Emergency Health is expanding rapidly. The breadth of the topics addressed by the abstracts range from prevention and mitigation strategies to patient care to public health. We are beginning to appreciate the magnitude of the domain of prehospital and in-hospital emergency care as well as the broad spectrum of public health. Of the abstracts submitted, $16 \%$ relate to emergency medical services, $16 \%$ to education and training, $16 \%$ to preparedness, and $10 \%$ to public health before, during, and after emergencies and disasters. The remaining topics are spread across many areas including civil-military collaboration, international law and ethics, humanitarian crises, mass-gatherings, pediatrics, psychosocial problems and interventions, the use of chemical, biological, nuclear, radiation, and explosive devices, and more.

The global impact and involvement in prehospital, emergency, and disaster health is evidenced by the broad spectrum of the origin of these important works: papers originate from 54 countries. Reports are provided from the developed countries to those that are undergoing rapid development.

The information contained in the submitted abstracts has been obtained using a variety of methods ranging from controlled, experimental studies to qualitative descriptions. It is important to note that anecdotal, descriptive reports gain significance when they are combined with other similar reports. Repeated observations progressively gain external validity when the same observations are made during several similar or dis-similar events. This applies to events from single car crashes to those that generate mass-casualties. The important issue is that the information is being obtained and shared-research is being done. The WADEM has the responsibility to configure the information presented into the most appropriate framework, and to integrate the organized information into our science.

When the broad scope of the free papers that will become part of this Congress are combined with the innovative structure into which the Congress is being organized, the potential value of this Congress becomes even more exciting. The Dutch Organizing Committees have taken great care to design a Congress that will be more interactive than ever before. The Congress will be organized around the structure of the Standing Committees and Task Forces of the WADEM, and will include novel approaches to the presentation of the material and the development of standards for integration into best practices. Importantly, the plans include careful reporting of every oral and poster session by their respective chairs and by rapporteurs, who will provide detailed summaries of the presentations in each session along with important conclusions. ${ }^{1}$ These summaries will include the probable impact of the information obtained from analysis of the posters and oral presentations as well as those from the innovative Targeted Agenda Programs, the integrated plenary sessions and special sessions conducted by the Human Actions in Crisis Department of the World Health Organization. In addition, the Congress will include: an all-day special program, "Understanding the Evolving Role of Nurses in Disaster Health Care", organized by the Nursing Section of the WADEM, a dissection of recent major events such as the Earthquake and Tsunami in Southeast Asia, the Pakistan Earthquake, Hurricanes Katrina and Rita, and more. The Joint Commission International, together with Yale New Haven Center for Emergency Preparedness and Disaster Response, the Pan-American Health Organization, and the WADEM will convene a two-day workshop of "Safe Hospitals" in which a process will be begun to develop: (1) consensus on standards and benchmarks for hospital preparedness; (2) a framework for strategies to achieve these standards through identification of appropriate benchmarks; and (3) evidence-based best practices to guide the preparedness activities.

Each of the attendees will receive summaries of each session, even those they were unable to attend. Special Hot Topics will include comprehensive discussions on possible pandemics, vehicular crashes, education, credentialing, and the development of standards for best practices. When all these elements are combined with the pre-Congress stateof-the-art learning sessions and post-Congress educational workshop on evaluation and research in disaster management, the relevance and impact of the Congress increases.

It is clear that public health, prehospital and in-hospital emergency care, hazard management, disaster epidemiology, damage mitigation, preservation of function, response to events, the loss of function, and recovery will receive a thorough inspection during this Congress. The outputs from this Congress will contribute more than any other conference has to the growth of the science of public health dur- 
ing and following a disaster and emergency health care. The results and the interactions between the participants will help to bring many areas of the world to a new standard of best practices; but, it will not do so without your involvement. I look forward to your participation in what is shaping up to be a testimony to the remarkable growth of disaster and emergency health.
...I am poor and naked, but $I$ am the Chief of the nation. We do not want riches, but we do want to train our children right. We could not take them with us to the other world. We do not want riches. We want peace and love.

Red Cloud [Makhpiya-luta], Late 19th Century, Sioux Chief

\section{References}

1. Birnbaum ML: Is this all? Prehosp Disast Med 2002;17(1):1-2. 